\section{MÃES NEGRAS EM LUTO: CONFIGURAÇÕES DA LITERATURA E DA CRÍTICA LITERÁRIA DIANTE DA VIOLÊNCIA RACISTA}

POR FABIANA CARNEIRO DA SILVA

\begin{abstract}
Based on the analysis of the novel Um defeito de cor, by Ana Maria Gonçalves, the article focuses on the topic of black motherhood, emphasizing the links between the ways in which this representation takes place in the literature of black authorship in Brazil and the critical repertoire that seeks, from several areas of knowledge, to explain the perverse racist mechanisms of obstruction to the exercise of motherhood by the black women of the country.
\end{abstract}

\section{KEYWORDS}

Um defeito de cor; Black motherhood; Literature and Racism.

Um defeito de cor; Maternidade negra;

Literatura e Racismo.

\footnotetext{
' Professora Adjunta do Instituto de Humanidades, Artes e Ciências (IHAC) da Universidade Federal do Sul da Bahia (UFSB) e vice-coordenadora da Licenciatura Interdisciplinar em Artes e suas Tecnologias. Doutora em Teoria Literária e Literatura Comparada pela Universidade de São Paulo (2017), mestre em Teoria Literária e Literatura Comparada pela Universidade de São Paulo (2012) e bacharel e licenciada em Letras (Português e Espanhol) também pela Universidade de São Paulo (respectivamente 2008, 2012). O presente texto integra o livro Ominíbú: maternidade negra em Um defeito de cor, o qual encontra-se no prelo pela editora EDUFBA.
} 
16 de junho... Hoje não temos nada para comer. Queria convidar os filhos para suicidar-nos. Desisti. Olhei meus filhos e fiquei com dó. Eles estão cheios de vida. Quem vive, precisa comer. Fiquei nervosa, pensando: será que Deus esqueceu-me? Será que ele ficou de mal comigo?"

Quarto de Despejo: diário de uma favelada (1960)

Carolina Maria de Jesus

Ele disse: 'Mãe, eu sei quem atirou em mim, eu vi quem atirou em mim. Foi o blindado, mãe. Ele não me viu com a roupa de escola?'.

Bruna Silva, mãe do jovem Marcos Vinicius da Silva, assassinado pela polícia em junho de 2018

Ao definir o projeto de sua carta como um pedido de desculpas ao filho, a narradora do romance Um defeito de cor, Kehinde, institui, à rememoração operada pela narrativa, o caráter de elaboração de uma perda. A forma como a perda é processada diz respeito ao confinamento da subjetividade da narradora em um entre-lugar, na medida em que a suspensão do encontro com o filho - sendo este indeterminadamente um corpo vivo ou morto -, confere às passagens finais do relato uma melancolia pungente, apontando para uma possível resistência ao trabalho de luto ${ }^{2}$. A transferência do afeto a um novo elemento, que está na base desse processo tal qual ele foi desenvolvido por Sigmund Freud, aparece como impedimento dado pelo contexto, mas também como reforço da agência da mãe, que se recusa

\footnotetext{
${ }^{2}$ Dirigindo-se ao interlocutor da carta, Kehinde afirma: "Seu desaparecimento foi pior que a morte de seu irmão, muito pior, porque ele eu sabia onde e como estava. Mas foi bom ter esperanças, pois acho que o destino resolveu aliviar a mão agora, e por isso não hesitei em deixar tudo para trás e partir" (GONÇALVES, 2006, p. 631).
} 
a fazê-lo ${ }^{3}$. A angústia por não saber o rumo que Luiz/Omotunde tomou associa-se à contrariedade dos sentimentos em relação ao pai que o vendev e a certo remorso pelas decisões tomadas num passado que não volta mais:

Durante todos esses anos, eu sempre me lembrei dele [Alberto, o pai] com ódio, e só agora, depois de relembrar esta história desde o começo, entendo tudo o que passou e que, apesar da mágoa, ainda consigo pensar nele com um pouco de carinho. Como terá sido para você? Tenho imensa curiosidade de saber disso, de saber até que ponto você conseguiu perdoá-lo e a mim também, de saber quanto você conhece desta história toda. Assumo minha parte de culpa, e por ela me penitenciei em cada um dos dias que se passaram, na esperança de que você entendesse isso e não sentisse tanta raiva. Nem tanto por mim, mas por você mesmo, para que seu coração estivesse mais livre e menos preocupado para poder traçar o destino grandioso que eu sempre soube estar reservado para você.(GONÇALVES, 2006, p. 564).

As passagens finais do romance incitam que entendamos a história retrospectivamente narrada, isto é, os deslocamentos de Kehinde, seus trânsitos geográficos, sociais, afetivos e identitários, sob o sentimento de dor e incompletude.As autocríticas que ela realiza estendem-se à forma como se relacionou com os outros filhos - "Por que será que tenho pelo menos um arrependimento em relação a cada um dos meus filhos? Arrependimento por falta

\footnotetext{
${ }^{3}$ Sobre as relações entre luto e melancolia ver o texto clássico de Sigmund Freud, Luto e Melancolia. FREUD, Sigmund; KEHL, Maria Rita; PERES, Urania T.; CARONE, Modesto e CARONE, Marilene (trad. Marilene Carone). Luto e Melancolia. São Paulo: Cosac Naify, 2011 e NATALI, Marcos Piason. A política da nostalgia: um estudo de formas do passado. São Paulo: Nankin Editorial, 2006. O desejo de encontrar Luiz faz da busca de Kehinde uma meta obstinada. Mesmo em África, tendo um oceano e alguns anos de distância como hiato em relação ao filho, ela não abandonou a procura: "[...] Comecei a receber relatórios muito claros e extensos a cada seis meses, explicando tudo o que estava sendo feito na sua busca e justificando todos os gastos. Mesmo que não justificassem, eu teria pago com muito gosto, deixando o Tico autorizado a não economizar quando o assunto fosse você. Em uma das cartas, ele tentou me desanimar, dizendo que já fazia muito tempo e eu estava gastando uma pequena fortuna, mas nem dei importância. A l̀yá Kumani, depois de visitar um babalaô, tinha me garantido que você seria encontrado, e esta afirmação, aliada à minha esperança, ao que sentia no meu coração de mãe, dizia que eu estava no caminho certo, e nele iria até o fim, até não ter mais jeito" (GONÇALVES, 2006, p. 850, grifo nosso).
} 
ou por excesso de zelo, mas nunca por falta de querer bem, e é isso que me consola" (GONÇALVES, 2006, p. 939) -, o que amplia a significância da dicção materna como traço central da narrativa e potencializa o desfecho do relato.

Um defeito de cor não tem como final um feliz encontro entre mãe e filho. Ao contrário disso, a despeito das conquistas alcançadas por Kehinde, a perda permanece no livro como ponta solta, irresolução que dificulta um balanço ou valoração estanque da trajetória narrada. No que se refere a esse melancólico desfecho, espelhando o romance no contexto de sua publicação, nota-se que o percurso de vida apresentado por Kehinde conecta-se a outras narrativas de mães negras no Brasil, as quais também são apartadas de seus filhos, mas que, diferentemente da narradora do romance, não raro deparam-se com os corpos inertes desses filhos assassinados cotidianamente por uma política genocida do Estado, que tem como alvo a população negra do país. Desse modo, o livro de Gonçalves encena um passado histórico que, apesar da distância cronológica, mantém duras conexões com o presente.

O trabalho de Ana Luiza Pinheiro Flauzina, Corpo Negro Caído no Chão: o sistema penal e o projeto genocida do Estado Brasileiro, concluído no mesmo ano de lançamento do romance, auxilia-nos a vislumbrar algumas das questões para as quais essa "ponta solta" do final da carta de Kehinde, enquanto potência semântica, remete. Desde a área do Direito, Flauzina objetiva explicitar como, ao longo de nossa história, isto é, passando pelos sistemas colonial-mercantilista, imperialescravista, republicano-positivista e chegando ao contemporâneo, neoliberal, o racismo faz-se categoria substantiva de estruturação do sistema penal brasileiro e fundamenta práticas genocidas do Estado. A autora evidencia, de modo contundente e inquestionável, as formas de materialização das vulnerabilidades em torno do segmento negro da população, "das políticas de esterilização [das mulheres] às limitações educacionais - passando por todas as interdições quanto à estruturação de uma identidade negra e, principalmente, pela produção em série de mortes" (FLAUZINA, 2006, p. 13). O racismo, negado a partir da resistente ideologia da democracia racial (que também opera no sentido de relegar a escravidão ao esquecimento), segundo ela, seria a prática que, na contemporaneidade, autorizao 
sistema liberal a realizar "a intervenção física para o controle ostensivo dos corpos". Em consonância com essa não declarada metodologia - que vem sendo, conforme a dissertação de Flauzina demonstra, sistematicamente atualizada -, o medo e a desumanização são atrelados a esses segmentos vulneráveis ${ }^{4}$ e tem nos homens jovens, na faixa dos vinte anos, o seu principal alvo:

No que se refere à taxa de homicídio, chegamos aos números de 20,6 em 100.000 para a população branca, e de 34,0 para a população negra. Isso representa uma proporção $65,3 \%$ maior de vítimas no segmento negro. Atentando especificamente para a juventude, os números apresentam uma diferença ainda mais drástica. A taxa de homicídios entre os jovens negros é $74 \%$ superior à dos brancos. No Distrito Federal, na Paraíba e em Pernambuco, por exemplo, a chance de um jovem negro ser vítima de homicídio é cinco vezes maior que a de um jovem branco (FLAUZINA, 2006, p. 112113).

Desse contingente de homicídios, cujos dados foram obtidos a partir da consulta em índices públicos de pesquisas, $20 \%$ das mortes seriam ocasionadas por intervenções policiais. A análise de Flauzina explicita, assim, a agência do Estado que, ao se instituir indiretamente do direito de matar, passa também a regular a vida. Mais do que isso, conforme ela salienta, o grau de vitimização da juventude revela um controle estatal sobre o futuro, isto é, torna visível um mecanismo de interdição da existência e reprodução, constituição de famílias, desses jovens.

Os estudos de Flauzina fazem reverberar o histórico de subtração dos filhos das mães negras no período escravista enformado pelo romance de Ana Maria Gonçalves ${ }^{5}$. No que se refere às mulheres negras no período neoliberal, para além das inúmeras formas de violência que as fazem figurar, dentre as mulheres, como

\footnotetext{
${ }^{4} \mathrm{~A}$ vulnerabilidade racial encontra-se vinculada à econômica. De acordo com Flauzina, a pobreza também tem no aspecto racial uma variante significativa de sua reprodução, conforme é possível notar pelos dados de pesquisa realizada pelo IBGE e citados por ela, segundo os quais, "entre o $1 \%$ mais rico da população brasileira, estão $87 \%$ de brancos, enquanto entre os 10\% mais pobres, 68\% são negros" (IBGE 13 fev. 2004. Apud FLAUZINA, 2006, p. 103).

${ }^{5}$ Em outros trabalhos, desenvolvo com vagar essa vereda temática.
} 
principais vítimas de homicídios, e das formas precarizadas de trabalho, que seguem alheando-as do convívio diário com seus filhos ${ }^{6}$, a pesquisa de Flauzina afirma que, sobretudo a elas, se destinam as práticas de histerectomia, a saber, a retirada, sob a incorrência de miomas, de seus úteros, conforme explica Suely Carneiro:

[...] o útero da mulher negra não tem valor, então qualquer mioma tem a indicação de retirada do útero. Souza aponta que as condutas médicas são diferentes diante de uma mulher se ela é negra ou se ela é branca. A conduta conservadora do uso de remédios ou expectantes é geralmente indicada para a mulher branca de qualquer classe social; ao contrário, para as mulheres negras, é indicada a histerectomia (CARNEIRO, 2005, p. 86 apud FLAUZINA, 2006, p. 104).

Vislumbra-se, assim, também na medicina, o funcionamento da categoria de raça como definidor de práticas que tendem a voltar sua atenção para a corporalidade branca e a negligenciar, segundo escreve Flauzina, as particularidades de cada segmento de mulheres que constituem a diversidade humana. Dentre o leque dos possíveis tratamentos dos miomas, aplica-se o mais radical (aquele que deveria ser última possibilidade) como procedimento "natural" e "recorrente" a ser realizado, porém, conforme a citada pesquisa de Vera Cristina e Souza mostra, apenas com as mulheres negras (às brancas busca-se, em maiores índices, os procedimentos de manter o quadro em observação ou optar por uma intervenção cirúrgica para a retirada somente dos miomas). Constata-se, pois, que a obstrução ao exercício da maternidade, seja pela dinâmica nefasta do subemprego, seja biologicamente por meio de práticas de esterilização e histerectomia, seja pelo assassinato de seus filhos, segue marcando a experiência de muitas mulheres negras no Brasil.

Esse contexto não é desconhecido e, pelo contrário, em sua visível concretude, tem sido denunciado há séculos. Entretanto, há obstáculos políticos e simbólicos para o seu reconhecimento que insistem em perdurar. Flauzina incursiona

\footnotetext{
- Destaca-se nesse caso, as rotinas extenuantes do trabalho doméstico em casas alheias que ainda encontra dificuldades de regulamentação.
} 
sua pesquisa em referências que explicitam como "o quadro simbólico que coloca negros e indígenas como barreiras para a civilização é a prerrogativa necessária para que os empreendimentos genocidas possam ser levados a cabo" (FLAUZINA, 2006, p. 32). Nesse sentido, ela recupera a problemática sobre a representação e cita um fragmento de Carlos Wedderburn do texto Um olhar sobre afrodescendentes (sic) das Américas e Caribe, o qual, por sua vez, remete-nos novamente a Um defeito de cor:

Quando você nega a presença física de uma população você está dizendo que você quer que ela desapareça e você fará de tudo para que ela desapareça fisicamente. Eé isso que estamos vendo de maneira bem clara quando você olha as novelas, as novelas estão falando! [...] - verão que todas as novelas latino-americanas são iguais - as populações negras são representadas ali como um defeito, uma imperfeição, e estão destinadas a desaparecer. Você não vai ver, por exemplo, famílias negras. A família é o quê? O lugar da continuidade, as famílias são pra reproduzir, você não vê famílias negras nessas novelas, o que você vê sempre são os elementos isolados. Em Venezuela, Peru, você vai de um país sul-americano para outro e vai ser sempre a mesma coisa, a mesma realidade. Quando há uma cara negra, é uma cara negra solitária, um homem negro sem mulher negra, sem filhos, sem pais, sem antecedentes... ou seja, algo destinado a acabar, algo que não tem raízes e nunca terá. $A$ prolongação, ontologicamente, não deve existir. Então, esta negação da presença africana nas Américas é um fator violento de genocídio simbólico (SANTOS, 2005, p. 35, apud FLAUZINA, 2006, p. 32-33, grifos meus).

O excerto interpreta a ausência de representação negra e, especialmente, de famílias negras, como um tipo de genocídio simbólico, uma forma de declarar que a presença africana nas Américas não deve existir. Em sentido próximo, em outros trabalhos, busquei explicitar como a imagem da "mãe preta" presente no cânone literário nacional parece proferir um discurso análogo, o qual encontra em Um defeito de cor um gesto disruptivo. Contudo, assim como o debate acerca do genocídio da população negra não tem no trabalho de Flauzina sua única versão e são muitas as vozes da intelectualidade negra que essa autora convoca para sublinhar o histórico de proposições sobre esse tema, entre elas Abdias do Nasci- 
mento, Sueli Carneiro e Lélia Gonzalez, além de campanhas dos movimentos negros que explicitamente em seus enunciados posicionam-se contra essas formas de extermínio, como a campanha da organização Reaja intitulada "Reaja antes que seja morto, antes que seja morta" -, a obra de Gonçalves também não surge como acontecimento isolado.

Se por um lado o romance dialoga de modo latente com certos conhecimentos oriundos da História, bem como das tradições orais, por outro, pode-se estabelecer correspondências entre a representação da maternidade de Kehinde e outras obras literárias de autoria negra produzidas no Brasil, na contemporaneidade e em diversos momentos históricos. Desse modo, para ficarmos apenas com os romances de autoria negra-feminina, podemos constatar significativas representações da mulher negra enquanto mãe na obra Ponciá Vicêncio (2003) de Conceição Evaristo, nas tramas de Carolina Maria de Jesus como o livro Quarto de despejo (1960) (cuja definição de gênero permanece em discussão pela crítica), no romance Negra Efigênia, paixão do senhor branco (1966), de Anajá Caetano e, aterrissando em pleno século XIX, momento transfigurado por Gonçalves, no romance Úrsula (1859), de Maria Firmina dos Reis. Este último, além de romance fundacional da literatura afro-brasileira, inaugura a literatura abolicionista no Brasil e surpreende por, segundo Eduardo de Assis Duarte, apropriar-se das técnicas do romance de fácil aceitação popular (no contexto das narrativas de folhetim) para "utilizá-las como instrumento a favor de seu projeto de dignificação dos oprimidos - e não apenas dos escravizados" (DUARTE, 2017, p. 227).

Apesar de Gonçalves não citá-lo na bibliografia, Úrsula pode ser lido em correspondência direta com Um defeito de cor, enquanto referência da linhagem literária que inscreve o "drama do escravizado" no Brasil e, em sentido estendido, posiciona-se de modo a denunciar e problematizar a ordem de subordinação e aniquilação que, em suas diversas atualizações ao longo dos processos históricos, a pesquisa de Flauzina apresenta. Nessa direção, faz-se necessário sinalizar que é por meio da voz de uma mãe,nomeada enquanto tal, a Mãe Susana, que o sistema escravista e a violência contra a mulher negra dele participante, é posto em cheque 
por Maria Firmina dos Reis? . Inserida como um discurso direto em meio a uma narrativa em terceira pessoa, a voz de Mãe Susana a constitui enquanto mulher negra dotada de subjetividade e que, desde um "profundo sentir", narra sua história, dando mostras da dor e da saudade geradas pelas perdas provocadas pela escravização:

[...] deram-me em matrimônio a um homem, que amei como a luz dos meus olhos, e como penhor dessa união veio uma filha querida, em que me revia, em que tinha depositado todo o amor de minha alma: - uma filha, que era a minha vida, as minhas ambições, a minha suprema ventura, veio selar a nossa tão santa união. E esse país de minhas afeições, e esse esposo querido, essa filha tão extremamente amada, ah Túlio! Tudo me obrigaram os bárbaros a deixar! Oh! Tudo, tudo até a própria liberdade! (REIS, 2017, p. 202).

Ao aconselhar e abençoar Túlio, a quem "Ihe serviu de mãe", a idosa africana relata sua vida pregressa ao rapto e a imigração forçada ao Brasil. Desse modo, antecedendo a representação complexa do período escravista realizada por Um defeito de cor, no texto de Firmina dos Reis "[...] pela primeira vez em nossas letras, a África é tematizada e surge como espaço de civilização em que o individual e o comunitário se harmonizam, em que se planta e se colhe, se casa e se fazem filhos, em que existem valores e sentimentos de família e de pátria" (DUARTE, 2017, p. 220). Entretanto, a morte de Túlio e a não alteração do estatuto de Mãe Susana, que como escravizada permanece alheada de tudo o que the era significativo, sinalizam os limites que circunscreviam a extraordinária narrativa de Firmina dos Reis

\footnotetext{
A dicção de outra mãe constitui o núcleo do conto "A escrava", da mesma autora. Nele, somos colocados diante da tragédia de Joana, que surge na narrativa como uma mulher em fuga a esconder-se de seu violento feitor. Tendo encontrado a proteção de uma abolicionista, já em estado agonizante, ela faz questão de narrar, em companhia do único filho, Gabriel, o motivo que lhe teria levado ao fatal sofrimento: a venda de seus outros dois filhos, Carlos e Urbano, aos oito anos de idade, pelo seu escravizador. Encena-se, assim, por meio de imagens e diálogos de notória força estética, o drama dessa mãe que narra em detalhes o momento em que seus filhos Ihe são retirados, bem como o desespero do único descendente que lhe restou (o conto também se destaca por dar voz e significância a esse filho, Gabriel): "Tenho a vista tão fraca...é a morte que chega. Não tenho pena de morrer, tenho pena de deixar meus filhos.... Meus pobres filhos!.... Aqueles que me arrancaram destes braços.... este que também é escravo!.... E os soluços da mãe, confundiram-se por muito tempo, com os soluços do filho." Após o seu relato, Mãe Joana morre e a narrativa caminha para o desfecho tendo o corpo morto da mulher como integrante das cenas finais (REIS, 2017, p. 201).
} 
em correlação ao seu contexto de época, na medida em que ela escreve em pleno funcionamento do regime escravista.

fato de que, dois séculos depois, tais tópicos, bem como certas imagens literárias, como a descrição do navio negreiro, também figurem como núcleo do romance de Ana Maria Gonçalves não tem significância pequena. O fio que alinhava a narrativa de Firmina dos Reis à de Gonçalves, bem como às demais mencionadas aqui, cada uma a seu modo e em consonância com seu momento de produção e com os projetos estéticos de suas autoras, vincula-as a uma sociedade em que o Lugar de Negro para referir-se ao livro de Lélia Gonzalez e Carlos Hasenbalg (1982), foi definido por uma lógica excludente, que tem na valorização dos elementos eurocêntricos, em detrimento dos aspectos afro-indígenas da constituição do território cultural, social e político do Brasil, seu motor. Verifica-se, assim, que a explicitação dessa lógica é uma demanda que convoca a representação do período escravista ainda como necessidade da literatura contemporânea. O surgimento de Um defeito de cor atende a essa demanda, mas numa perspectiva que, a sua vez, incorpora todo o histórico de mobilizações e articulações negras que busca(ra)m a alteração dessa ordem, histórico levantado no mencionado texto de Gonzalez. Em certa medida, tal efetivação é responsável pelos novos horizontes imaginativos e formais que distanciam essa obra das possibilidades vivenciadas e expressas por Firmina dos Reis.

A voz da mãe africana ressurge, então, para narrar a compra de sua alforria, a volta à África, a constituição de uma nova família e o desejo de resgate do vínculo deixado no Brasil. Compartilhando de um contexto em que, conforme demonstra Jaime Ginzburg, o gênero testemunho passa a ser produzido no país sob a chave da reflexão sobre a exclusão social, a obra de Gonçalves, como outros títulos desse segmento indicados pelo crítico, também coloca em cena uma narradora que "[...] pode ser examinado[a] como um[a] narrador[a] em confronto com um senso de ameaça constante por parte da realidade" (GINZBURG, 2012, p. 53). Sendo assim, a dimensão testemunhal da enunciação de Kehinde se dá, entre outros aspectos, na medida em que ela, por diversas vezes, relata a proximidade com a morte e, nessa direção, constituiuma "escrita de sobrevivente", a qual "se vincula à memória 
daqueles que não sobreviveram. Nesse sentido, escrever é também uma forma de dar túmulo aos mortos, para que não sejam esquecidos"' (SELIGMANN-SILVA, 2003, P. 55, apud GINZBURG, 2012, p.54). ${ }^{8}$

O teor testemunhal do romance produz uma memória que, na contramão da historiografia até pouco tempo concebida como "oficial", evoca a presença dos negros e negras que tiveram sua existência abreviada pela violência do sistema escravista - como são os destinos, na trama literária, de Taiwo, a irmã de Kehinde, Dúrójaiyé, sua avó ou Fatumbi, seu professor e amigo -, ou obnubiladas por ele, tais como as figuras de Luíza Mahin e Luiz Gama. Em gesto correlato, em sua elaborada construção do interlocutor do relato, o livro permite que centralizemos nossas atenções nas vidas muitas que ainda são constrangidas e/ou ceifadas pela dinâmica racista da estruturação nacional. A linearidade do texto, bem como a incorporação de procedimentos de escrita realista, estão subordinados à moldura introdutória da narrativa e à situação de performance enunciativa explicitada no final do texto. Desse modo, há um questionamento da referencialidade da linguagem que, em aproximação com os estudos sobre testemunho apresentados por Ginzburg, pode ser entendido como resultante da associação entre linguagem e violência, de modo que a dicção da narradora, ao ser caracterizada pela dor, pela falta e pela incompletude, distancia-se de uma narração realista que se faz como imagem da totalidade social. ${ }^{9}$

Em sua integral realização, Um defeito de cor posiciona-se na contramão da articulação profunda entre violência, poder e literatura que engendrou parte do cânone nacional e que, segundo Ginzburg, produziu um histórico de agressões ao

\footnotetext{
Sobre o caráter testemunhal de Um defeito de cor, Eduardo de Assis Duarte (2015, p. 186) escreve: "Além de recobrir a ficção com a autoridade do testemunho, o emprego da primeira pessoa pela voz narrativa dramatiza a tomada de consciência da personagem perante a violência. $O$ tom inocente da menina que, ainda na África assiste à agressão da mãe pelos guerreiros inimigos, contrasta com o horror da cena e o suaviza. Já a narrativa da mulher estuprada, que assiste à sodomização e castração do amado, adensa a crítica, sobretudo quando a estende para além-mar e lembra o costume primitivo que transformava escravos em eunucos".

9 De acordo com Ginzburg (2012, p. 54), citando João Camilo Penna (2003, p. 304): "O testemunho se vincula, nesse sentido, a movimentos de resistência. Sua compreensão exige perceber uma vida política dotada de multicentralidade. Nessa perspectiva, um indivíduo não é entendido em uma concepção burguesa, e sua constituição não se restringe a determinações nacionais".
} 
potencial crítico da literatura, fazendo da crítica ética uma prática restringida no Brasil. Nesse sentido, ele escreve:

Em um país que no século XX passou por duas longas ditaduras e ainda hoje sofre com as heranças da tradição patriarcal e dos regimes autoritários, a aspiração de uma abordagem da literatura voltada à ética e aos direitos humanos depende essencialmente de uma política da memória literária. O que deve ser lembrado, o que deve ser lido? O que tem valor, o que é literariamente importante? (GINZBURG, 2012, p. 220)

A associação entre análise estética e reflexão ética é abordada, pelo crítico, como elemento basilar para os estudos que queiram se debruçar sobre os textos de testemunho. Para além disso, porém, suas proposições permitem que estendamos tal necessidade de articulação do pensamento para a leitura de outras obras da literatura produzidas nesse território. Se, em termos gerais, como uma análise de Um defeito de cor pode evidenciar, "a civilização ocidental procurou, de modo ambivalente, enquanto sustentava e incentivava práticas da violência, criar condições para o silenciamento a respeito de seus agentes" (GINZBURG, 2012, p. 222), parece ser de competência ética da literatura, assim como do exercício crítico, sem dispensar a significância da localização do estético nessas práticas, desnaturalizar as experiências traumáticas imprimidas à comunidade negra no país e explicitar os projetos que constituíram a identidade nacional como "totalizante, não conflitiva e fechada emsimesma" (GINZBURG, 2012, p. 225).

Esforço análogo adquire respaldo e densidade filosófica nos escritos do teórico Achille Mbembe, o qual, após reconhecer que "o grande acontecimento de nosso tempo foi a Europa ter deixado de ser o centro do mundo" (MBEMBE, 2014, p. 264), parece elevar a escala das proposições de Flauzina sobre o Brasil, ao afirmar ser o racismo o substrato que legitima a opressão capitalista em nível global. Desse modo, partindo da investigação acerca do termo-conceito "Negro", Mbembe soma-se ao empenho de evidenciar o pluralismo do mundo em contraposição ao reducionismo europeu, isto, é "[...] a tendência instintiva de uma civilização eminente e prodigiosa que chega a abusar do seu prestígio para provocar um vazio à sua 
volta ao reconduzir abusivamente a noção de universal às suas próprias dimensões; por outras palavras, pensando o universal a partir dos seus próprios postulados e através de suas próprias categorias" (MBEMBE, 2014, p. 265). Ele explica como à palavra "Negro", em sua concepção eurocentrada, foi atribuído o poder de "coisificar" e "degradar", de forma que o campo semântico em que ela circula estabelece semelhança com as ideias de "morte", "assassinato" e "desaparecimento" (MBEMBE, 2014, p. 256-257). Coube, então, aos indivíduos marcados por tal termo a subversão e ressignificação dele, remetendo-o à "[...] luta obstinada pela liberdade e pela indomável esperança" (MBEMBE, 2014, p. 268). Desse modo, a apreensão do romance de Gonçalves sob a rubrica de literatura negra implica a exposição das constrições à maternidade negra nele configuradas, mas também a resiliência que caracteriza o trajeto de Kehinde e rechaça uma identidade vitimizadora. Assim como ela, a despeito da violência concreta e simbólica do racismo, outras mães resistem e inscrevem nas geografias do território chamado de brasileiro a fertilidade enquanto capacidade de criação e sublevação, fazendo-nos reconhecer a existência de outras epistemes que desafiam, deslocam e desconstroem essa "razão negra ocidental" descrita por Mbembe.

Há luto e lágrimas, mas a urgência do grito "Parem de nos matar!"10 convive com a necessidade de não se definir apenas pela falta. Narra-se em Um defeito de cor em pleno mar, isto é, desde uma embarcação que não mais se apresenta como o espaço de morte, isto é, aquele terrível tumbeiro" que surge no início da trama, e sim como um veículo que propicia à narradora o olhar para o seu passado transfigurado, então, em promessa de um futuro. Essa cena, lida como metáfora para a condição da mulher negra em diáspora no Brasil, evoca a busca pela constituição de si, a qual, desde uma fratura irreversível, exige formas alternativas de pensamento e apreensão do mundo. Tal proposição coaduna-se à reflexão de Gonçalves quando ela escreve em matéria publicada pelo suplemento Pernambuco:

Na tentativa de encontrar caminhos, lembro-me do que escreveu a poeta, romancista, ensaísta e documentarista canadense Dionne Brand, em seu maravilhoso A map to the

\footnotetext{
${ }^{10}$ Referência ao livro da escritora Cidinha da Silva (2016), no qual, segundo a própria autora, são apresentados "em crônicas textos opinativos sobre racismo, branquitude e privilégios raciais, ao tempo em que são destacadas pessoas e atitudes que resistem a essas ações destrutivas da humanidade dos negros".

"Lembrando que "tumbeiro" deriva de "tumba", termo, de diversas maneiras, associado à morte.
} 
door of no return. É sobre como, a partir do momento em que nossos ancestrais atravessaram esta porta em África, a Porta do não Retorno, sob a qual deveriam abandonar todas as memórias, passamos todos a habitar um não lugar. Um ponto que é, ao mesmo tempo, real e imaginário, uma coleção de lugares que também são metáforas de todos os outros lugares onde fomos parar, espalhados pelas Américas. 'Ter o próprio pertencimento alojado em uma metáfora', diz Dionne Brand, 'é um enredo luxuoso; é como habitar uma alegoria, ser um tipo de ficção. Viver na Diáspora Negra é, penso eu, viver como um ser fictício - uma criação dos impérios, mas também uma autocriação. É ser alguém vivendo dentro e fora de si mesmo. É entender-se como signo estabelecido por alguém e ainda assim ser incapaz de escapar dele, a não ser em momentos radiantes de simplicidade transformados em arte. Ser uma ficção à procura de sua metáfora mais ressonante é ainda mais intrigante.' (GONÇALVAS, 2017)

A evocação de Brand permite que a autora de Um defeito de cor apresente como possibilidade de existência para a mulher diaspórica seu enredamento na trama do ficcional. A tentativa de elaboração de um "mapa para a porta do não retorno" no texto de Brand figura, então, como gesto poético que dá a ver o conflito entre o pertencer e o não pertencer, o qual teria na imagem da "porta" uma senha cifrada que vincula o passado e o presente (Brand (2002, p. 77) escreve: "Water is the first thing in my memory").

A assunção do literário desse modo concebido o investe de um significado particular, que recobre toda a narrativa do romance Um defeito de cor e confere à obra a complexidade e o vigor que desafiam a tarefa crítica. As formas que a literatura negra e, em especial esse romance, encontra para perfazer-se diante da violência racista apropriam-se de um disponível repertório ocidental, mas reconfigurando categorias e relações tidas por esse acervo como "naturais e universais". Por isso, notamos, em acordo com Leda Maria Martins quando ela pensa a literatura de autoria negra-feminina e escreve:

O viés identitário, o revisionista, o historiográfico, o discursivo, o performático, dentre outros, podem nos fornecer entradas fecundas na algaravia dessa produção, tanto da mais longínqua quanto da mais recente, mas se tornam redutores, se postulados como sínteses exclusivas e totalizadoras da experiência, antes de tudo, literária (MARTINS, 2007, p. 79-80). 
A crítica que se imbui do diálogo com tais obras, requer sensibilidade e perspicácia para apreender uma escrita que performatiza o ser enquanto "pertencimento alojado em uma metáfora". A disponibilidade para o questionamento dos referenciais eurocêntricos, que insistem em recalcar a potência dessa escrita e o senso de responsabilidade ética diante de uma produção que surge também da dor, da morte, da violência, parecem igualmente necessários.

O romance Um defeito de cor faz-se prisma que possibilita o traçar de um caminho de leitura comprometido com a construção dessa delicada e precisa mirada, a qual, por sua vez, dê lugar a urgência de formular pertinentes indagações, fundamentadas na interface entre a literatura e as sociedades que coexistem no território identificado como Brasil. As questões críticas formuladas e desenvolvidas sob essa orientação estabelecem intrínseca relação com a História e acionam elaborações que reeditam o passado, buscando, desde o presente, perscrutar as condições da comunidade negra e da própria literatura como chaves para se contrapor à ameaça de morte e construir uma necessária nova imagem de futuro.

\section{Referências Bibliográficas}

BRAND, Dionne. A Map to the Door of No Return: Notes to Belonging. Toronto: Vintage Canada, 2002.

DA SILVA, Cidinha. \#Parem de nos matar!. São Paulo: Editora ljumaa, 2016.

DUARTE, Eduardo de Assis. Margens da História: a revisitação do passado na ficção afro-brasileira. In: SISCAR, Marcos e NATALI, Marcos Piason [Orgs]. Margens da democracia: a literatura e a questão da diferença. Campinas: Editora da Unicamp, Editora da USP, 2015.

. Úrsula e a desconstrução da razão negra ocidental [posfácio]. In: REIS, Maria Firmina dos. Úrsula: romance; A escrava: conto. Belo Horizonte: Editora PUC Minas, 2017.

FLAUZINA. Ana Luiza Pinheiro. Corpo Negro Caído no Chão: o sistema penal e o projeto genocida do Estado Brasileiro. Dissertação de mestrado. Brasília: Universidade de Brasília, 2006.

FREUD, Sigmund. Luto e Melancolia. Tradução Marilene Carone. São Paulo: Cosac Naify, 2011. 
GINZBURG, Jaime. Crítica em tempos de violência. São Paulo: Editora da Universidade de São Paulo, Fapesp, 2012.

GONÇALVES, Ana Maria. Um defeito de cor. São Paulo: Record, 2006. . Uma ficção à procura de suas metáforas. Suplemento

Pernambuco, n. 132, fev. 2017. Disponível em:

http://www.suplementopernambuco.com.br/edições-anteriores/67bastidores/1783-uma-ficção-à-procura-de-suas-metáforas.html. Acesso em: 09/ 2017.

GONZALEZ, Lélia; HASENBALG, Carlos. Lugar de negro. Rio de Janeiro: Marco Zero, 1982.

MARTINS, Leda Maria. A fina lâmina da palavra. O eixo e a roda. Belo Horizonte, v.15, 2007, p. 55-94.

MBEMBE, Achille. Crítica da razão negra. Tradução Marta Lança. Lisboa:

Antígona, 2014.

REIS, Maria Firmina dos. Úrsula: romance; A escrava: conto. Belo Horizonte: Editora PUC Minas, 2017.

NATALI, Marcos Piason. A política da nostalgia: um estudo de formas do passado. São Paulo: Nankin Editorial, 2006.

SILVA, Fabiana Carneiro da. Maternidade negra em "Um defeito de cor": história, corpo e nacionalismo como questões literárias. Tese de doutorado. Universidade de São Paulo, 2017. Disponível em:

http://www.teses.usp.br/teses/disponiveis/8/8151/tde-28032018-104918/en.php. 